Open Scientist Handbook • OSH

\title{
Against Patents in the Academy
}

Bruce R. Caron

Published on: Mar 10, 2021

DOI: $10.21428 / 8 b b b 7 f 85 . b e 5 d f e b f$

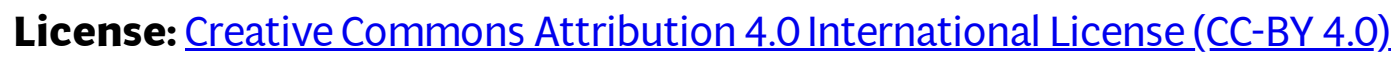




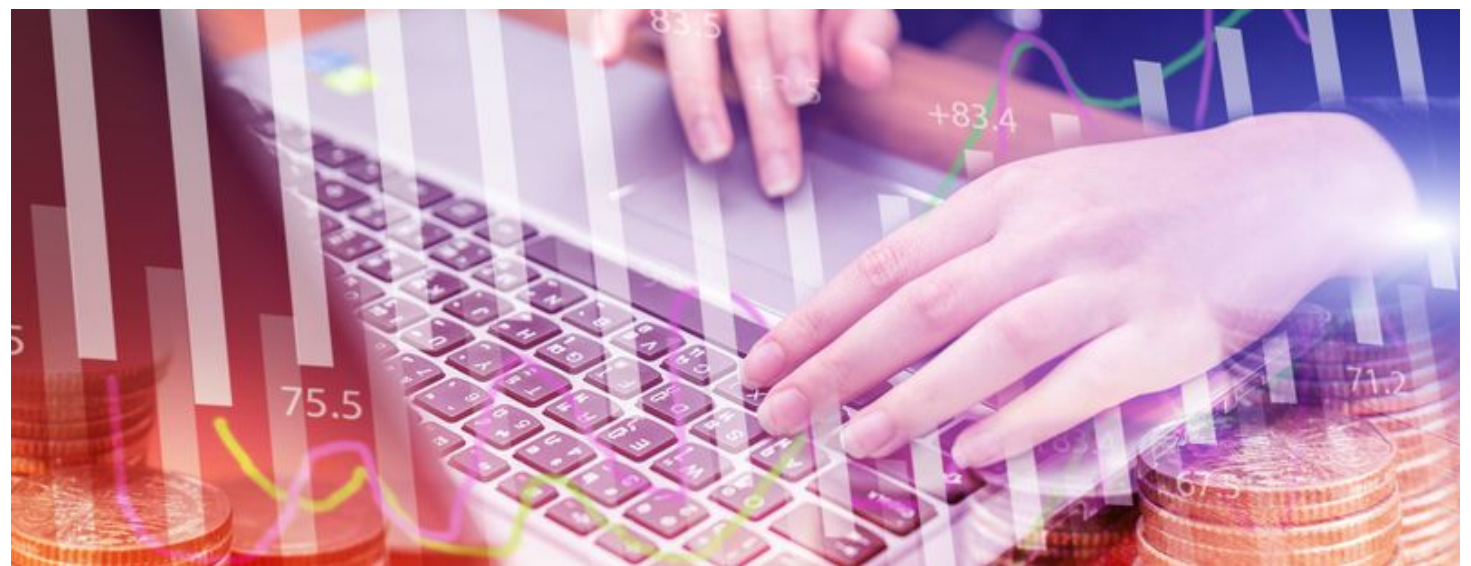

With a poor return of value, and a huge overhead for research, patents are a bad investment for the academy

\section{It's time to eliminate patents in universities: Step up to Open}

"It is true that many people in science will scoff if you try to tell them about a scientific community in which ideas are treated as gifts. This has not been their experience at all. They will tell you a story about a stolen idea. So-and-so invented the famous such and such, but the man down the hall hurried out and got the patent. Or so-and-so used to discuss his research with his lab partner but then the sneaky fellow went and published the ideas without giving proper credit. He did it because he's competitive, they say, because he needed to secure his degree, because he had to publish to get tenure-and all of this is to be expected of departmentalized science in capitalist universities dominated by contractual research for industry and the military" (Hyde 2009).

In researching the forty years of allowing publicly funded primary research results to be patented in the US, what becomes clear is that for every success story there are scores of negative outcomes. The bureaucracy that universities build to capture the "value" of research as patents (Welpe et al. 2015), the administrative burden on researchers to conform their work to the process of patent-making (Stodden 2014; Graeber 2019), the perverse career pressure to produce more patents (Edwards and Roy 2017), the downstream roadblocks for sharing the research (NAS 2018): the entire ecosystem (or egosystem) of doing patents argues against their benefits to the academy. The underlying tension between the university's long-term mission as a wellspring of new public knowledge and the market's desire to acquire and privatize new discoveries remains at issue here (Foray and Lissoni 2010). 
The Handbook is not a primary source for arguments around patents, and will only point to some major issues and a handful of available resources on this topic. Gerald Barnett (Accessed August 31, 2020) has assembled a useful resource on the web for those interested in university patent issues. The Handbook argues that open science works best within a shared resource commons, where the neoliberal market is held apart, but likely never fully absent, for the duration. Open science and closed knowledge transfer practices do not play well together.

You might work in one of very few select sub-disciplines (usually within bio-medical or IT research) at one of the few universities where university patents have had some historical financial returns. But for the other ninety-five percent of science, and for the academy as a whole, the value of sharing research far exceeds whatever near-term monetized return might be available. Newfield (2016) summarizes the situation this way:

"The point here is not that the University of California and American research were doing badly. To the contrary, they were producing the normal market results of doing research very well, which (with rare exceptions) is to spend lots of money rather than to earn it. The market results of innovative research are, as research results, close to nil. This is as it should be. The purpose of innovative research is innovation-discovery, invention, and scientific progress. This research has great long-term and social value that could not be captured as licensing revenue or estimates of the market value of patents.

The contribution of the research university can best be appreciated in broader, postmarket terms. The research university was designed to investigate every topic of conceivable public interest, from astronomical physics to agricultural genetics and everything in between. Major commercial returns accrued to research in a fairly narrow band of fields largely found in information technology and biomedicine...." 


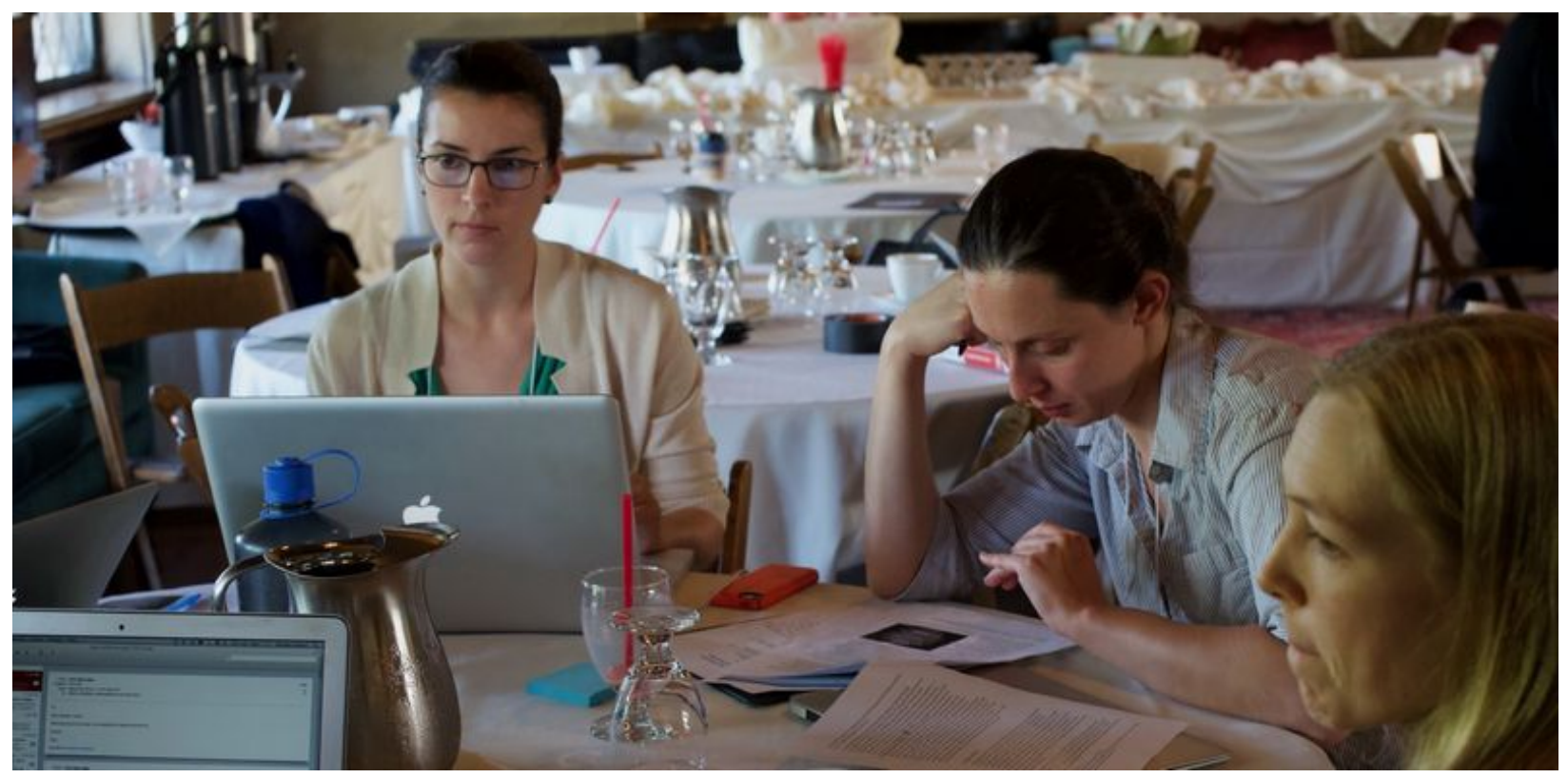

Workshops only work when research ideas can be openly shared

University research results have also, historically, been "transferred" to the academy, industry, and the public through a diverse portfolio of channels (publications, workshops, conferences, etc.). Patents interfere with these other channels. "[W]idespread patenting and restrictive licensing terms may in some cases hamper, rather than promote, technology transfer from universities to industry. These policies may also obstruct the process of scientific research (Mowery et al. 2001). Foray (2004) puts it like this: "Most studies on these issues show that this evolution [toward patenting basic research] represents a real risk of irremediable alteration of modes of cooperation and sharing of knowledge in the domain of basic research. When there is nothing left but exclusive bilateral contracts between university laboratories and firms, there are forms of quasi-integration that undermine the domain of open knowledge." 


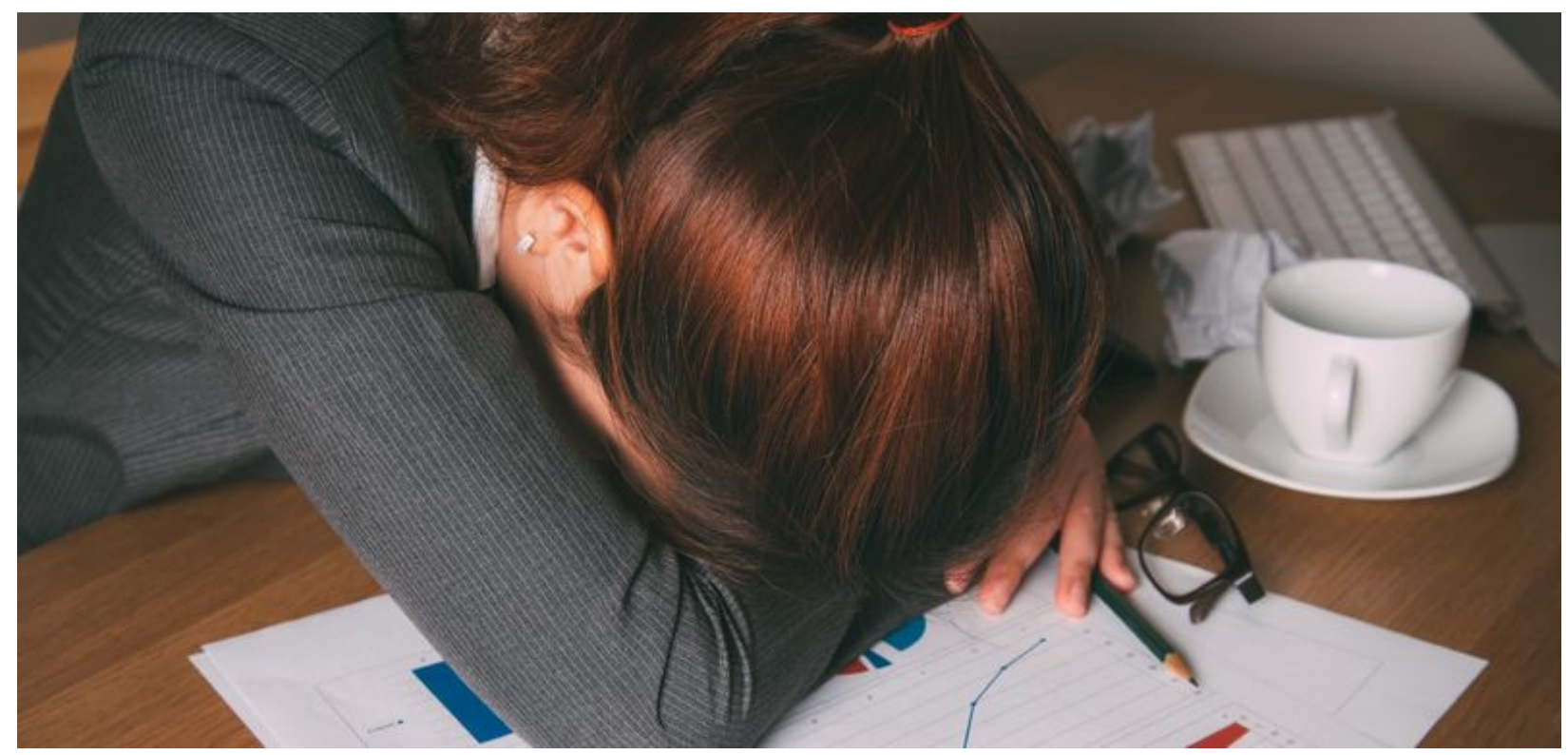

The number of university patents has exploded in recent decades. Patents have become a gameable metric; another administrative burden that takes time away from doing research.

Remembering here that science is infinite play (See: Learning infinite science play). The actual returns on research are mostly "postmarket" in value. Open sharing accelerates returns in the near term and compounds research value over time. Universities achieve their value proposition through a broad range of research and educational activities. The availability of market returns from patents for a small segment of university research threatens to warp the research opportunity landscape, and the normative internal incentives (including curiosity) for research (Strandberg 2005).

"In an age when ideas are central to the economy, universities will inevitably play a role in fostering growth. But should we allow commercial forces to determine the university's educational mission and academic ideals? In higher education today corporations not only sponsor a growing amount of research - they frequently dictate the terms under which it is conducted. Professors, their image as unbiased truth-seekers notwithstanding, often own stock in the companies that fund their work. And universities themselves are exhibiting a markedly more commercial bent. Most now operate technology-licensing offices to manage their patent portfolios, often guarding their intellectual property as aggressively as any business would. Schools with limited budgets are pouring money into commercially oriented fields of research, while downsizing humanities 
departments and curbing expenditures on teaching" (Press and Washburn 2000; Accessed August 25, 2020).

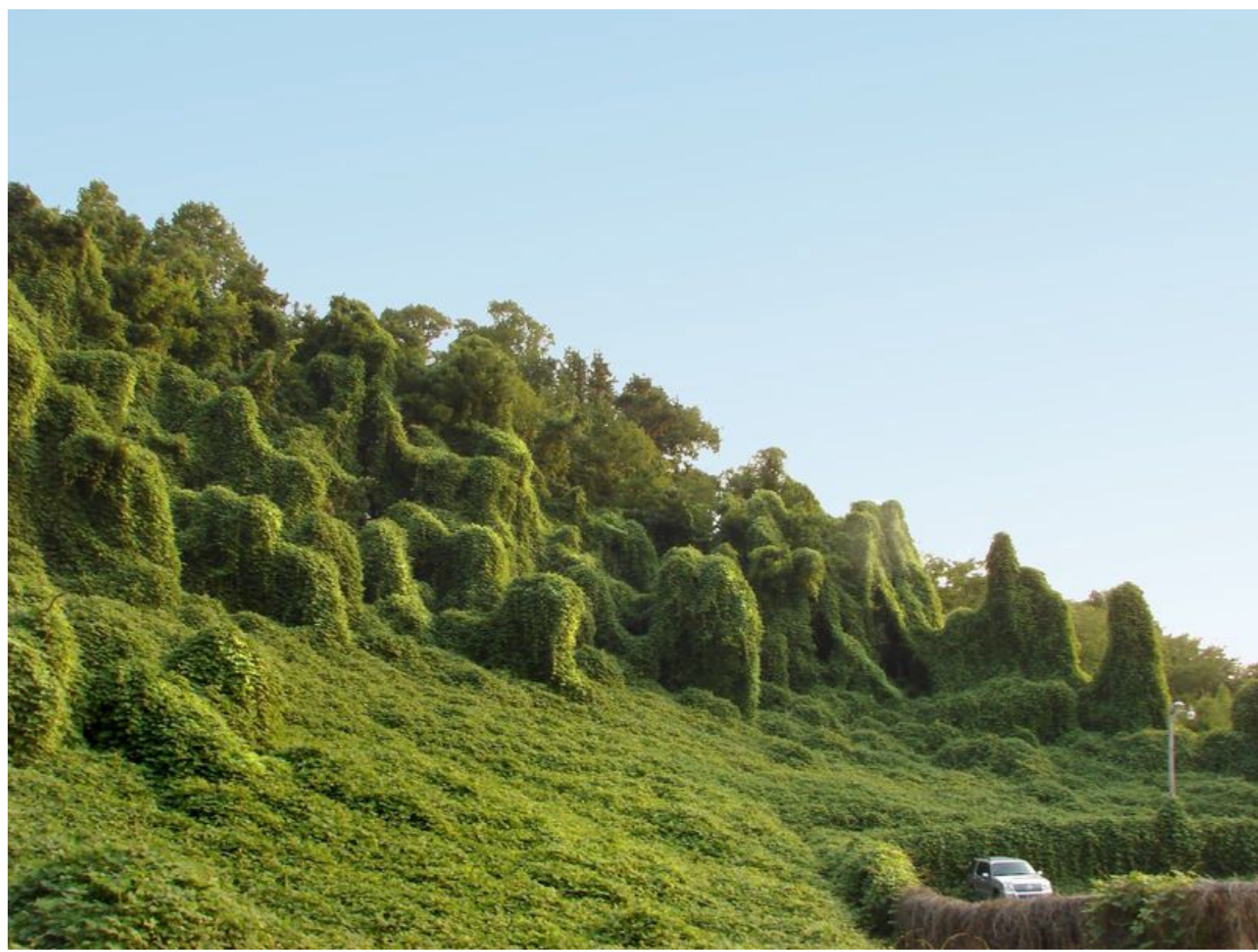

University patents grow like intellectual property kudzu. They choke oncepromising research pathways and deter new research as they cover the innovation opportunity landscape. (Photo: Katie Ashdown [CC BY 2.0]/Flickr)

\section{Time to act}

Open science looks ahead to a future where the capacity to share research findings is optimized through scholarly commons, collaboratives that steward research goods through the decades, and across the planet (See: scholarly commons; Also, Madison et al. 2009). Patents subtract intellectual property and value from these commons: "[T]o the extent that universities surround the work of their scientists with thickets of patents, the upshot can be what Heller and Eisenberg [1998] call a scientific 'anticommons' in which ideas and concepts that in the public domain might spur discovery and innovation are zealously guarded by the institutional owners who value income more than innovation" (Ginsberg 2011). Researchers may also shy away from research arenas where existing patents impede new research (Foray and Lissoni 2010). 
Looking ahead, the rapid increase of mostly under-performing (in terms of financial gain) patents creates no-research zones across formerly attractive knowledge domains. This growing patent infestation-intellectual property kudzu clogging the shared open resource pool - may be an unfortunate near-future end game for university patents, strangling new research. But a better plan is to clear away these anticommons today.

In the US, the repeal of Bayh-Dole - the act that permitted universities to patent federally-funded research - would open up old (and now, new), long-term research sharing capacities (Barnett, May 10, 2020; Accessed August 26, 2020). Putting the market-incentive genie back in its bottle will help universities shrink their administrative overhead, help researchers manage their own research interests, and help the academy get on with the real business of science: its mission to openly share knowledge within an abundant gift economy in order to foster new discoveries of benefit to all humans. However, Bayh-Dole is only one of a couple dozen post-WWII US laws that regulate and channel intellectual property flows among universities, government labs, and industry (Slaughter and Rhoades 2010). These laws were created to knit university research outputs into the surrounding neoliberal marketplace. Each of these laws needs to be reassessed for its impact on the other knowledge dissemination flows universities have long used, and on the long-term mission of academic organizations. As the U.S. Code is a maze of regulations that are stacked on previous laws, simply repealing one of these (such as Bayh-Dole) is rarely a good fix. Its removal simply exposes the problems created by the previous laws (Barnett, August 31, 2020; Accessed September 1, 2020).

There are two options around Bayh-Dole. The first would be a new national law that revokes and replaces large parts of Bayh-Dole without repealing it; a kind of Bayh-Dole antidote that neutralizes the previous law and adds another wart on the dimpled surface of the U.S. Code. The problem here, as John Wilbanks (personal communication) surmises: universities would likely find contractual means to work around the new law and keep doing what they do in a somewhat weaker mode. A university culture of neoliberal, short-term gain will find a way to circumvent the new law. The second option is more pervasive and effective over time: change university culture to neutralize Bayh-Dole. "Any university could in effect repeal Bayh-Dole by creating an open scholarship favorable patent policy. Claim nothing up front. Require no disclosure of inventions" (Barnett, ibid). Here is a concrete cultural change that open scientists can take to their faculty senates and board of regents. Barnett (ibid) spells it out with some precision: 
"Thus, the shortest route to open is to insist that universities comply with the extraneous requirement of the nonprofit standard patent rights clause at $37 \mathrm{CFR}$ 401.14(f)(2)-require the written agreement, making inventors parties to each funding agreement, and declining to take any interest in any invention the inventors might make under the funding agreement (which in turn brings the university into compliance with the extraneous requirement at 37 CFR 401.14(g) (1)). With compliant (f)(2) agreements in place, inventors have no obligation to disclose subject inventions to the university or to the federal government so long as the inventors do not make the inventions know[n] to the inventors' patent personnel and the university does not claim ownership of the inventions and require the inventors to make the inventions known to the university's patent personnel."

Need more detail? Barnett (September 8, 2020; Accessed September 9, 2020) gets to the heart of your new university policy. If your mission is to seed new knowledge to the world, your university can do this a lot better without exclusive patents.

Once the university's culture has pivoted to open, technology transfer offices (downsized appropriately) could play a part in encouraging open and free licensing agreements that seed new knowledge out to the public. "Universities have, for a very long time, seen themselves primarily as dedicated to the advancement of knowledge and human welfare through basic research, reasoned inquiry, and education. The longstanding social traditions of science have always stood apart from market incentives and orientations. The problem is therefore one of reawakening slightly dormant cultural norms and understandings, rather than creating new ones in the teeth of longstanding contrary traditions" (Benkler 2006). 


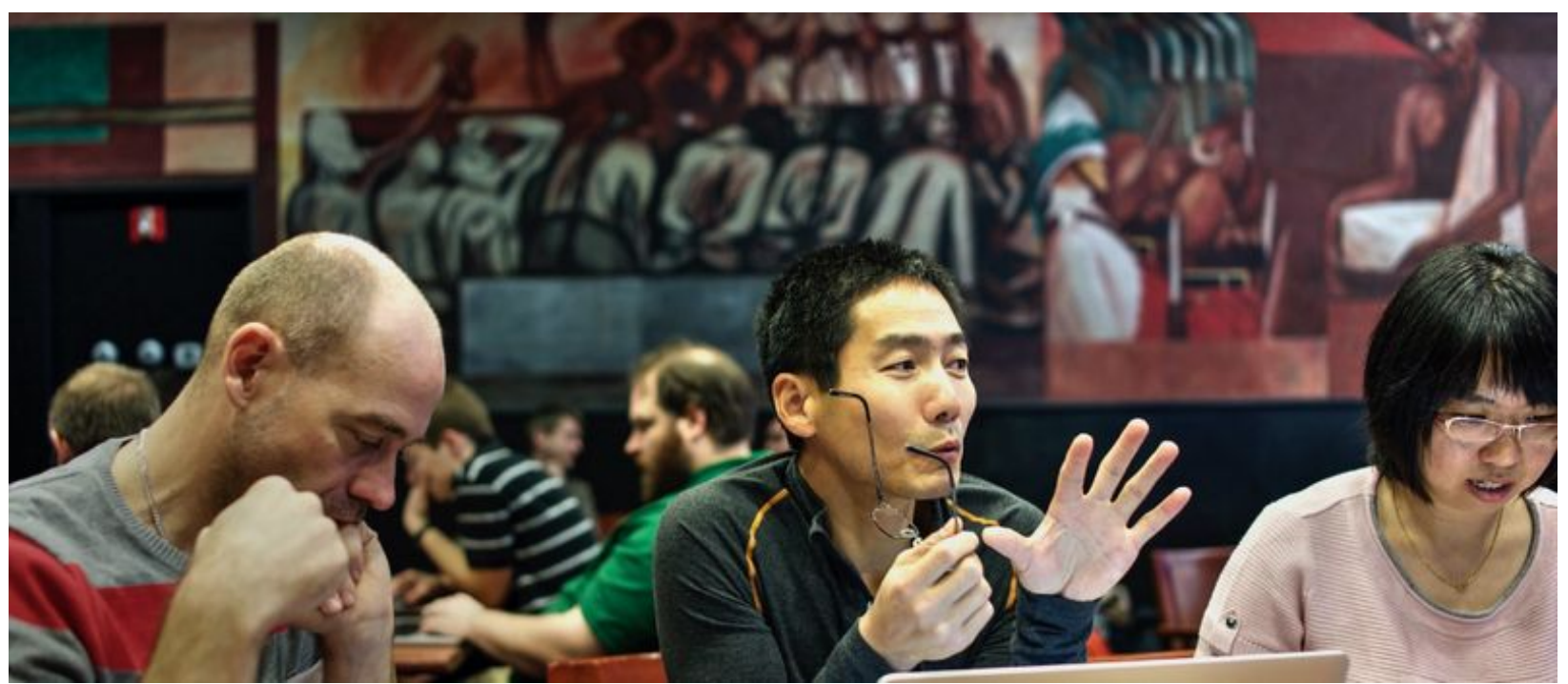

Research ideas are conversation starters. Openly discussed, they foster creative moments of serendipity. Patents are conversation enders. They lead to silence.

Research ideas are conversation starters. Openly discussed, they foster creative moments of serendipity. Patents are conversation enders. They lead to silence.

\section{Life after patents}

There are some universities, and hundreds of active academics - and associate vice chancellors and assistant deans - who have benefited financially (or defended their job salaries) from university-patent-driven technology-transfer practices enabled by these laws. There is an argument that universities need this new source of funding in the face of other budget cuts; that universities should realize immediate returns of the value of their research. However, such an argument already discounts other, and greater, value that open research might provide in the absence of patents. The larger corrective to current budget issues begins with a more complete understanding of the sum of the value of the public goods created by universities.

Newfield (2016) details the path to more fully optimize the value proposition for universities:

"We saw that the road to the public university's decline was paved with a long, diffuse campaign against its status as a public good. The practical effects were disastrous. The demotion of public good status forced university managers to pare their institutions' overall value to a narrow and fragile private fraction of the total (the wage premium over high school graduation). This paring undermined the university's ability to deliver the indirect, nonmarket, and social benefits that make up the majority of its total value, and its ability to deliver the emerging 
private market good, which were creative capabilities, which paradoxically could not be supported by private good market calculations. The failure to make a strong case for both individual and mass creativity, which depended on rebuilt support for research as well as instruction, weakened the case for rebuilt public funding. Collateral damage includes weaker understanding of the public value of academic freedom for faculty, of due-process-based job security for all university employees, and of the need to convert student work time to study time.

The solution requires restoring the university's public good status. A first step would be basic accounting reform that quantifies the value of indirect effects, nonmarket value, and social benefits with the same dutiful attentiveness that accounting applies to the private market benefit of higher salaries" (Newfield 2016).

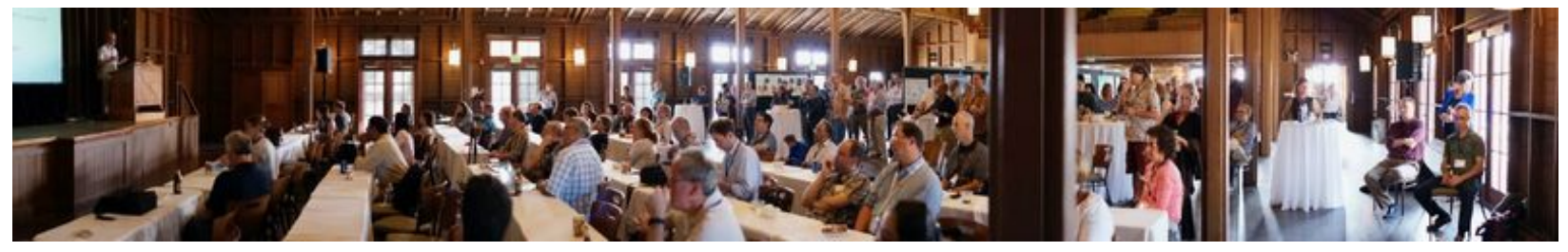

\section{Open science promotes multiple pathways for sharing new knowledge.}

Open science looks to build on the longer-term historical/future mission of the academy as a wellspring for creative outcomes, both research and learning. All through this Handbook, you can find information and explanations on how open science cultural changes - many of which merely revitalize lost cultural norms - build innovation capacity and internal incentives that can drive science forward. Because of the compounding feature of open research collaborations, open science is likely to also improve the direct financial return on research within society, even though universities do not capture this return through patents.

Newfield (2016) proposes a multi-stage recovery from the neoliberal university. As open science works inside the academy to optimize the complete value of doing scholarship, this added value can become the subject of an active conversation with government funders and legislatures, who will be tasked to reinvest in the higher education endeavor as a public good with a solid value proposition. 


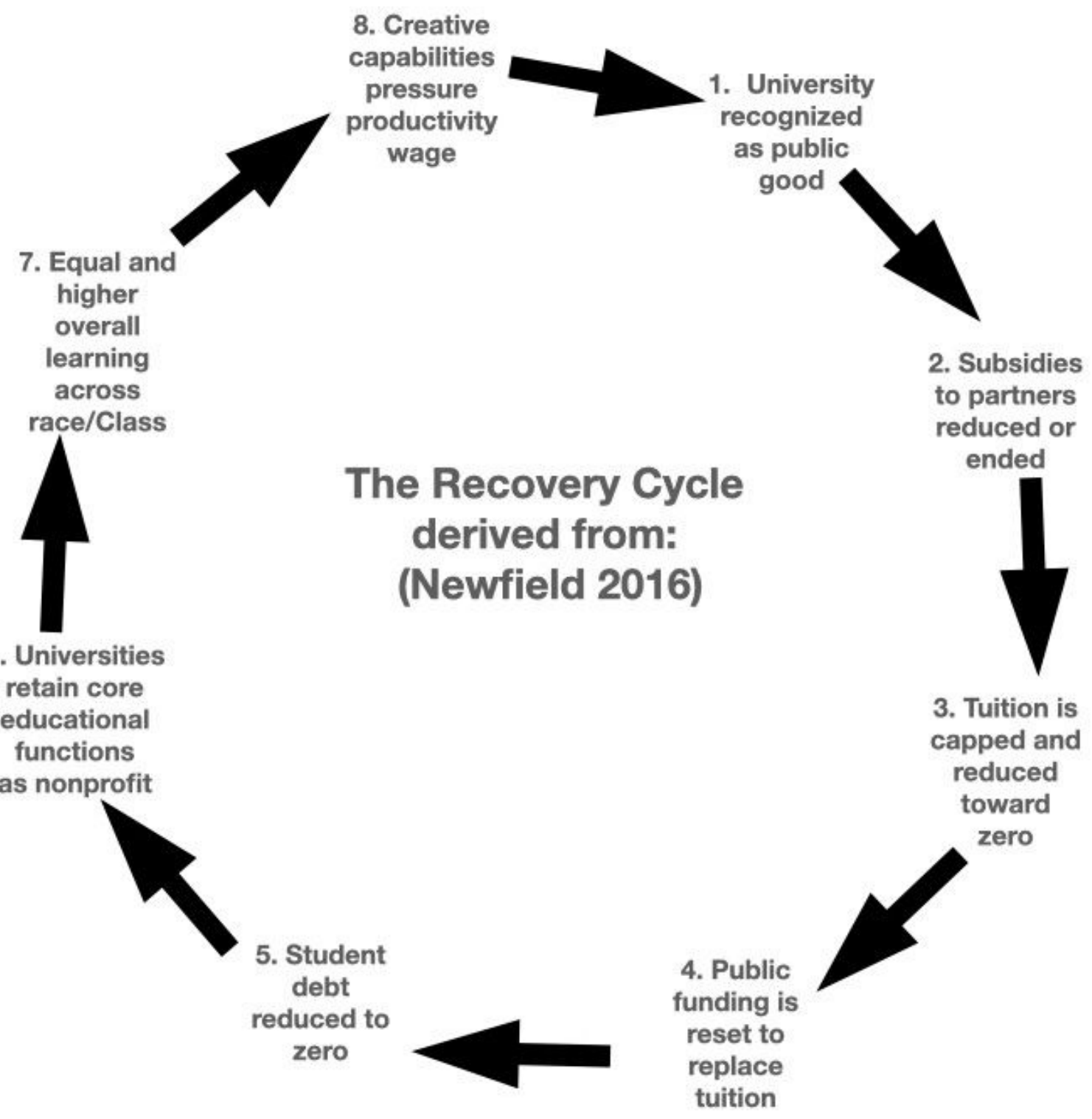

Recovery from the private-goods-only evaluation of the university value proposition begins with a new appreciation of the larger creative capacity universities offer society. Open science harnesses this capacity, making it more available to public notice and, one hopes, support.

\section{Your take on this}

You can help your university become more open by working toward a post-patent culture. What is your sense, from your own experience working with and around university-held patents? How much of your time is spent dealing with demands for 
patentable technology transfer? Has the presence of existing patents caused you to shift your research topic? The future of patents is one more conversation within the cultural shift toward open science. Your ideas are valuable, perhaps these should be gifted to the academy (See: Idea Gardening).

\section{Bibliography: Open Scientist Handbook References}

